\title{
(Des)conhecimento, adoecimento e limitações impostas pelo HTLV: experiências de mulheres soropositivas
}

\author{
(Un)Familiarity, illness and limitations imposed by HTLV: \\ experiences of HIV positive women
}

\author{
Ana Clarissa Cerqueira dos Santos ${ }^{1}$, Danielle de Jesus Soares ${ }^{1}$, \\ Maria da Conceição Costa Rivemales ${ }^{1}$
}

\begin{abstract}
Resumo
Introdução: O estudo buscou identificar o conhecimento de mulheres acometidas pelo HTLV acerca da infecção, além de descrever a experiência do adoecimento e limitações impostas pelo vírus. Método: Trata-se de uma pesquisa descritiva, com abordagem qualitativa. Participaram 12 mulheres acometidas pelo HTLV, atendidas no ambulatório de Infectologia de um hospital universitário em Salvador (BA) e no Centro de Testagem e Aconselhamento em Santo Antônio de Jesus (BA). A análise deu-se com base no Discurso do Sujeito Coletivo. Resultados: Os resultados demonstram que é notável o desconhecimento em relação ao HTLV. O adoecimento é representado por dor, comprometimento dos membros inferiores e relaxamento dos esfíncteres. O HTLV impõe limitações nas atividades de vida diária e acarreta mudanças no cotidiano e na vivência das mulheres soropositivas. Conclusão: Os dados empíricos confirmam a importância da realização de estudos, análise e discussão sobre o HTLV para o desenvolvimento de políticas e estratégias para o enfrentamento das doenças decorrentes da infecção.
\end{abstract}

Palavras-chave: HTLV; doença crônica; enfermagem.

\begin{abstract}
Introduction: The study sought to identify the knowledge of women affected by HTLV about the infection, in addition to describing the illness experience and limitations imposed by the virus. Method: This is a descriptive research with a qualitative approach. Participants were 12 women affected by HTLV receiving care at the Infectious Diseases Ambulatory of a university hospital in Salvador (BA) and the Center for Counseling and Testing in Santo Antonio de Jesus (BA). The analysis took place from the collective subject discourse. Results: The results show that there is a remarkable ignorance about the HTLV. The illness is evident from the pain, impairment of the lower limbs and relaxation of sphincters. HTLV imposes limitations in daily activities and causes changes in daily life and experiences of HIV positive women. Conclusion: The empirical data confirm the importance of studies, analysis and discussion of the HTLV for the development of policies and strategies for coping disease resulting from infection.
\end{abstract}

Keywords: HTLV; chronic illness; nursing.

\footnotetext{
${ }^{1}$ Centro de Ciências da Saúde, Universidade Federal do Recôncavo da Bahia (UFRB) - Santo Antonio de Jesus (BA), Brasil.

Trabalho realizado no Hospital Universitário Professor Edgar Santos (HUPES) - Salvador (BA), Brasil; e no Centro de Testagem e Aconselhamento (CTA) Santo Antônio de Jesus (BA), Brasil.

Endereço para correspondência: Ana Clarissa Cerqueira dos Santos - Rua 5 Portas, 393 - Centro - CEP: 44320-000 - Conceição da Feira (BA), Brasil -

Email: santosanjoclarissa@gmail.com
}

Fonte de financiamento: nenhuma.

Conflito de interesses: nada a declarar. 


\section{INTRODUÇÃO}

O vírus linfotrópico de células T humanas (HTLV), pertence à família Retroviridae, apresenta quatro tipos: HTLV-1, HTLV-2, HTLV-3 e HTLV-4. O HTLV-1 foi descoberto em 1980, é o mais prevalente em todo mundo e associa-se a patologias como leucemia/linfoma de células T do adulto (ALT) e paraparesia espástica tropical (TSP) (doença neurológica), também conhecida como mielopatia associada ao HTLV-1 (HAM)1. O HTLV-2 foi isolado em 1892 e, até o presente momento, há poucas evidências de sua associação com o surgimento de doenças; assim, encontram-se descritos na literatura casos esporádicos de sua associação com mielopatia, polineuropatias de predomínio sensitivo e quadros de miopatia inflamatória² ${ }^{2}$ Segundo Wolfe ${ }^{\mathrm{i}}$,

[...] o HTLV-3 foi descoberto em 2 habitantes assintomáticos do Sul de Camarões, cujas amostras de soro apresentaram sorologias indeterminadas para HTLV. O HTLV-4 foi descrito entre africanos caçadores de carne silvestre ${ }^{3}$.

A infecção por esse vírus encontra-se disseminada mundialmente. Sua transmissão se dá por via vertical, por meio da amamentação e canal de parto, via horizontal, mediante relação sexual, e via parenteral, pela transfusão sanguínea ou pelo uso compartilhado de instrumentos perfurocortantes contaminados ${ }^{4}$.

Estimativas baseadas em prevalências conhecidas indicam que o Brasil possui o maior número absoluto mundial (2,5 milhões) de indivíduos infectados pelo HTLV1.

Desde quando fora descrito, o HTLV tem sido associado a um espectro abrangente de doenças. A maioria dos indivíduos infectados permanece assintomática, no entanto esse vírus pode causar patologias graves. De 3\% a 5\% dos indivíduos acometidos evoluem para alguma patologia associada ao HTLV 5,6 .

Leucemia/linfoma de células T do adulto (ALT) consiste em uma neoplasia de linfócitos $\mathrm{T}$ maduros, associada à infecção pelo HTLV-1. Ocorre frequentemente entre indivíduos dos 40 aos 60 anos de idade, sugerindo um período de latência de algumas décadas. Já mielopatia associada ao HTLV-1 - paraparesia espástica tropical (TSP/HAM) é uma manifestação neurológica cujo principal comprometimento é o déficit motor dos membros inferiores, de caráter progressivo e invalidante ${ }^{5,7}$.

Vale destacar que a soropositividade para o HTLV é mais acentuada nas mulheres do que nos homens. A explicação mais provável para essa diferença é a transmissão por via sexual mais eficiente do homem para a mulher e transfusões sanguíneas mais frequentes em mulheres ${ }^{1}$.

Com essa pesquisa, buscou-se identificar o conhecimento de mulheres acometidas pelo HTLV acerca da infecção, além de descrever a experiência do adoecimento e limitações impostas pelo vírus. Apesar de ser uma infecção sexualmente

\footnotetext{
Wolfe ND, Heneine W, Carr JK, Garcia AD, Shanmugam V, Tamoufe U, et al. Emergence of unique primate Tlymphotropic viruses among central African bushmeat hunters. Conferência sobre Retrovírus e Infecções Oportunistas, 2005.
}

transmissível, incurável e que pode comprometer os estados físico e neurológico do indivíduo, é escassa a divulgação de informações sobre tal enfermidade, seus sintomas e vias de contaminação, mesmo entre profissionais de saúde.

\section{MÉTODOS}

Trata-se de um estudo descritivo, com abordagem qualitativa, realizado mediante a utilização de dados secundários da base de dados elaborada para o projeto de pesquisa intitulado "Vivência da sexualidade: representações das pessoas soropositivas para o HTLV". Os dados foram coletados no ambulatório de Infectologia de um hospital universitário, centro de referência para tratamento das pessoas acometidas pelo HTLV, localizado na cidade de Salvador (BA), e no município de Santo Antônio de Jesus (BA), por meio das pessoas cadastradas no Centro de Testagem e Aconselhamento (CTA), no período entre março e setembro de 2011.

Participaram do estudo 12 mulheres soropositivas e sintomáticas para a infecção pelo HTLV atendidas nos serviços anteriormente citados, tendo como critérios de inclusão: serem adultas, terem diagnóstico de soropositividade para o HTLV há pelo menos dois anos e aceitarem participar espontaneamente do estudo.

Como técnica de coleta, utilizou-se a entrevista em profundidade, que permite acesso aos dados de difícil obtenção por meio da observação direta ${ }^{8}$. As entrevistas foram gravadas e posteriormente transcritas para melhor análise e preservação da fidedignidade dos dados.

Para a análise dos dados, elegeu-se como estratégia metodológica o Discurso do Sujeito Coletivo (DSC), que consiste na reunião, em um só discurso-síntese homogêneo redigido na primeira pessoa do singular, do pensamento de uma coletividade, de sujeitos distintos?.

Para obter os DSCs, foi necessário o cumprimento das seguintes etapas: significados, organização das falas em um discurso-síntese e análise do discurso.

O presente estudo respeita os aspectos que envolvem a pesquisa com seres humanos, mediante a aprovação do projeto pelo Comitê de Ética em Pesquisa do Complexo Hospitalar Professor Edgar Santos, sob o protocolo $n^{\circ} 116 / 2010$, e solicitação, aos participantes do estudo, da assinatura do termo de consentimento livre e esclarecido.

\section{RESULTADOS E DISCUSSÃO}

A faixa etária predominante das participantes do estudo foi entre 50 e 59 anos (33,3\%). Quanto à escolaridade, predominaram as que possuíam estudo fundamental $(58,3 \%)$, tendo $33,3 \%$ relatado ser casadas. No quesito etnia/cor, $66,6 \%$ declararam-se pardas.

Os discursos do sujeito coletivo seguintes expressam o quanto o HTLV é desconhecido, o que dificulta a associação 
do vírus e dos sintomas apresentados. Na maioria das vezes, o diagnóstico ocorre muito depois do início dos sintomas e os principais sinais são limitações físicas que interferem no cotidiano das mulheres.

O DSC1 exprime como o HTLV é uma infecção desconhecida tanto pela população quanto por profissionais de saúde, favorecendo o erro no diagnóstico e, consequentemente, no tratamento e acentuando o aparecimento de sequelas associadas ao vírus. O DSC2 exprime os sinais e sintomas apresentados, alguns iniciados antes do conhecimento da infecção, sendo os mais comuns dor, comprometimento dos membros inferiores e relaxamento dos esfíncteres. Por fim, o DSC3 revela as principais limitações físicas ocasionadas pela infecção e sua interferência na vida social das soropositivas, visto que com os movimentos dos membros diminuídos ou ausentes as mulheres tornam-se dependentes de outras pessoas.

DSC1: (des)conhecimento da infecção pelo HTLV

Eu não sabia, não tinha esclarecimento nem conhecimento do diagnóstico. Procurei o médico; primeiro consultei lá no interior e ele disse que era crise reumática, tomei antibiótico o tempo todo e não vi resultado. Ele disse: "eu acredito que a senhora não é caso para ortopedista e sim para angiologista”. Fui ao Centro Médico, quando cheguei lá, passou aqueles exames para fazer das pernas, fiz os exames e deu normal. O médico me indicou fazer fisioterapia, por causa das dores nas pernas e me mandou procurar um neurologista. O neurologista passou um remédio e melhorei, não sentia mais nada, depois comecei a sentir de novo. Depois me encaminhou também para um infectologista. Fiquei com um neurologista, um infectologista, um reumatologista e um cardiologista; aquele grupo sabe, para saber qual é o problema. Fiz tudo isso pagando, gastei mais de $R \$ 1.000$. Só descobri porque teve uma campanha para coleta de doação de sangue. Eu fiz, tiraram o sangue para o teste passou tempo, depois colheram novamente, sei que me chamaram umas três vezes e no fim detectou que eu tinha o vírus do HTLV. Se não fizesse isso talvez nunca fosse descobrir, porque eu fazia todos os exames e dava normal, tudo o que eu fazia de exame dava normal. Depois fui encaminhada pra cá eu já estava com incontinência urinária, não conseguia andar sozinha, precisava pegar em alguém, precisava da ajuda de um cacetinho. Quando fui ao dentista e ele perguntando, perguntando, eu disse: "Doutor eu tenho HTLV". Ele disse: "o que é isso?" Eu disse: "Ah! doutor eu não sei te explicar não. Eu sei que tenho o HTLV e faço acompanhamento, mas eu não sei nem te explicar como é. Sei que é uma doença; não pega fácil, só pega na relação sexual. Ele disse: "É o HIV?" Aí eu perguntei: "O que é HIV?" Aí ele ficou assim... porque tem médico que não sabe, a verdade é essa, e quando a gente fala faz um escândalo. Mas, eu acho que o correto é a gente falar, porque sabendo vai pesquisar, vai entender, vai estudar e pode ajudar outras pessoas.

O DSC1 demonstra o desconhecimento tanto das soropositivas quanto dos profissionais de saúde acerca do HTLV, fazendo-os não relacionar a sintomatologia apresentada com as doenças associadas ao vírus.

Assim, o HTLV é pouco conhecido pelos seus portadores, pelos profissionais de saúde e pela população em geral, sendo, frequentemente, confundido com o vírus da imunodeficiência humana (HIV), causador da síndrome da imunodeficiência adquirida $(\mathrm{AIDS})^{5}$.

Como o diagnóstico clínico é incomum, porque o profissional solicitado dificilmente desconfiará da presença do HTLV, o indivíduo é encaminhado para diversos profissionais, alguns de difícil acesso pelo Sistema Único de Saúde, por causa das grandes filas de espera, sendo necessário o pagamento de consulta. Além disso, várias pessoas começam a fazer tratamento com o diagnóstico errado, como no DSC1.

$\mathrm{O}$ fato de sujeitos mesmos sintomáticos precisarem fazer uma espécie de peregrinação, em vários especialistas de saúde, na busca de um diagnóstico que explique seus problemas, é uma consequência da invisibilidade do vírus. A autora considera que esse lapso de tempo acontece porque as doenças associadas ao HTLV são, ainda hoje, negligenciadas, sem proposta de enfrentamento específico em Saúde Pública ${ }^{10}$.

Outra despesa não menos importante é a significativa perda de tempo até a descoberta correta do diagnóstico. Nesse período, os sintomas vão agravando-se, e quando terminada a investigação, as limitações físicas já estão instaladas. Existe dificuldade no correto diagnóstico, aconselhamento e tratamento do indivíduo por se tratar de uma infecção pouco divulgada entre os profissionais de saúde e a população em geral ${ }^{11}$.

Essa negligência decorre do fato de ser uma doença com longo período de latência, cursando de forma assintomática para o maior número de soropositivos, e por não possuir um alto perfil de morbimortalidade.

No Brasil, a infecção pelo HTLV pode ser considerada um problema de Saúde Pública que não foi devidamente assumido e que, por esse motivo, permanece “órfão", sem políticas específicas em seu enfretamento ${ }^{10}$.

Embora seja uma doença endêmica no Brasil, a triagem sorológica é obrigatória e disponível somente para os doadores de sangue, tendo sido iniciada em 1993, com a Portaria $n^{\circ} 1.376$, do Ministério da Saúde, que diz:

O candidato à doação não deve ser portador de doenças infecciosas por sua transmissibilidade através da transfusão de sangue, componentes e derivados. São excluídos definitivamente os indivíduos infectados pelo vírus: HTLV-I/II. É obrigatório em todas as unidades coletadas o teste para exclusão dos anticorpos anti-HTLV-I/II ${ }^{12}$.

Apesar de um exame laboratorial ser suficiente para fazer a triagem sorológica desse vírus, detectando anticorpos no sangue examinado, não é habitual a solicitação de exame para esse fim nem é ofertada a realização de teste rápido para diagnóstico desse vírus pelo Sistema Único de Saúde.

Além da dificuldade de realizar o teste, a população testada depara-se mais uma vez com informações obscuras, permanecendo sem orientações relevantes à infecção. Às vezes, o profissional de saúde confunde o HTLV com o HIV por sua similaridade semântica. 
Após descobrirem a infecção, as pessoas enfrentam, ainda, a dificuldade de acessar os serviços de saúde, seja na dimensão geográfica, organizacional ou econômica. O conceito de acessibilidade está ligado a oportunidades iguais de acesso a certas atividades ou serviços entre os indivíduos ou grupos sociais ${ }^{13}$.

$\mathrm{Na}$ dimensão geográfica, o obstáculo do acesso ao serviço de saúde são as barreiras físicas, como a longa distância entre a residência da pessoa e o local de tratamento. No âmbito organizacional, o empecilho é a forma como esse serviço está estruturado para receber o usuário acometido por esse vírus, podendo haver déficit no acolhimento, dificuldade na marcação de consultas e na consonância de horário. Outra barreira que deve ser colocada no arcabouço organizacional é a invisibilidade que sofrem as pacientes por parte de alguns profissionais e gestores de saúde, pois o HTLV é uma doença crônica de curso lento e incerto.

Já no aspecto econômico, a objeção à acessibilidade se dá por prejuízos causados pela perda de dias no trabalho, afastamento do trabalho por motivo de doença e elevado custo com o tratamento, além da necessidade de deslocamento, que demanda um custo adicional.

Ainda em relação às barreiras físicas, percebe-se a necessidade de uma melhor estrutura arquitetônica, visando à diminuição dessa barreira nos serviços de saúde, sobretudo nos hospitalares. Nesse sentido, medidas públicas deveriam ser adotadas para minimizar tais dificuldades e otimizar o acesso dos deficientes físicos a esses serviços, garantindo-lhes, dessa forma, o direito de ir e vir livremente ${ }^{14}$.

Visto que a infecção não tem cura, a assistência consiste no acompanhamento da doença. Para isso, o diagnóstico precoce é crucial, permitindo intervenções nas fases iniciais da doença, minimizando ou retardando os efeitos incapacitantes. Como os sintomas assemelham-se aos de outras doenças, é imprescindível também o diagnóstico diferencial para o correto tratamento.

Destarte, o domínio de informações sobre o HTLV é de suma importância, porque possibilita o correto aconselhamento às pessoas soropositivas.

O aconselhamento configura-se como um momento, ou mesmo uma técnica destinada a estabelecer um diálogo com o usuário para fornecer-lhe informações sobre a doença e realizar a escuta ativa, valorizando a demanda de cada usuário ${ }^{15}$.

É essencial estabelecer claramente a distinção entre as infecções causadas por HIV e pelo HTLV, sobretudo em relação ao potencial de morbidade e letalidade. É importante ressaltar que essas informações precisam considerar o nível de escolaridade e capacidade de compreensão das pessoas ${ }^{10}$.

Enfim, fica explícito no DSC1 que o desconhecimento por leigos e profissionais de saúde, bem como a falta de políticas de saúde voltadas às pessoas acometidas pelo HTLV, compromete a assistência prestada a essas pessoas, sejam assintomáticas ou sintomáticas. Dessa forma, reitera-se a importância da construção de um saber teórico e prático específico a respeito do vírus para uma assistência mais efetiva e específica aos necessitados.

DSC2: percebendo o adoecer: foi doendo, doendo e tomou o corpo todo

Comecei a sentir dores nas pernas terríveis. Começou a doer o calcanhar, do calcanhar foi doendo, doendo e passou para o joelho, depois passou para a coluna e tomou o corpo todo. Pensei que ia perder a perna, uma fraqueza muito grande nos ossos. Quando a dor começava tinha que deitar logo porque não aguentava de tanta dor. Sentia muita dormência principalmente nas pernas, nas mãos, nos lábios, dores de cabeça terríveis. Comecei a sentir perda de urina, muito antes do diagnóstico. Relaxei os nervos de umas condições que não controlava a bexiga e sentia muita dor; não conseguia segurar a urina de jeito nenhum. Comecei a usar absorvente, e depois a colocar um pano na cama, porque às vezes quando acordava estava toda molhada. Eu fazia xixi o dia todo, fazia xixi na roupa o tempo todo, era assim desse jeito.

O DSC2 revela que o HTLV pode acarretar sérios sintomas, alterando o cotidiano das mulheres afetadas. Dentro do amplo espectro de manifestações relacionadas a esse vírus, destaca-se a paraparesia espástica tropical/mielopatia associada ao HTLV-I $(\mathrm{HAM} / \mathrm{TSP})^{16}$. Essa doença causa paraparesia e paralisia dos membros inferiores e relaxamento dos esfíncteres vesicais, que pioram progressivamente.

Os sintomas apresentam-se lentamente. As limitações impostas pelo vírus têm início insidioso e progressivo de fraqueza muscular nos membros inferiores e espasticidade associadas, em grau variado, a distúrbios esfincterianos e sensitivos ${ }^{17}$.

Histopatologicamente, observa-se um processo inflamatório crônico, decorrente de infiltração linfocitária. $\mathrm{O}$ maior sítio de acometimento é a medula torácica baixa, embora todo o neuroeixo possa estar envolvido. A paraparesia espástica tropical acomete mais mulheres e adultos jovens, entretanto nenhuma faixa etária encontra-se livre de adoecer ${ }^{17}$. Em uma pesquisa realizada com 206 pacientes, os sintomas mais frequentemente observados foram diminuição da força em membros inferiores e consequente distúrbio de marcha, relatados por 157 pacientes (76,2\%), presença de bexiga neuropática em $182(88,4 \%)$ e constipação intestinal em 161 (78,2\%) dos casos. O relato de dor esteve presente na metade dos pacientes ${ }^{18}$.

Entre os principais sinais e sintomas da patologia, destacam-se distúrbios da marcha, fraqueza e enrijecimento dos membros inferiores, dor em região dorsolombar e incontinência urinária. A marcha torna-se espástica em diferentes graus de acometimento. A espasticidade constitui-se no principal fator limitante e leva os acometidos a precisarem de auxílio na locomoção. Muitas vítimas dessa doença passam a depender de outras pessoas em suas atividades de vida diária (AVDs) básicas, como higiene, locomoção e alimentação ${ }^{19}$.

A presença dessas limitações provoca mudanças na qualidade de vida das pessoas. $\mathrm{O}$ aumento da frequência urinária limita as 
atividades de vida diária, levando a alterações dos sentimentos, do relacionamento pessoal e ao isolamento social. Ademais, altera o sono, a energia e as emoções das mulheres incontinentes. Esse impacto torna-se maior para mulheres que trabalham fora de $\operatorname{casa}^{20}$.

A paraparesia espática tropical associada ao HTLV é uma doença rara, no entanto grave, incapacitante e compromete as atividades de vida diária. As acometidas, silenciosamente, têm redução da autoestima, tornando-se deprimidas, angustiadas e irritadas.

DCS3: deficiência e dependência: prisioneira do próprio corpo

Eu vivia alegre, brincava, ouvia música, saia, me distraia, ia à praia, gostava de ir para a seresta com minha amiga; dava muita risada; depois fiquei desse jeito. Fico presa dentro de casa! Não saio porque não tenho vontade. Eu penso que vou empatar; as pessoas que saírem comigo não vão se divertir e nem eu vou me divertir, eu estou ali precisando de cuidados e as pessoas tendo que cuidar de mim! Um sofrimento de cadeira de rodas, ser dependente dos outros! Enfim, minha vida social mudou muito, gostava muito de sair, gostava muito de me distrair; hoje em dia eu vivo presa.

No DSC3, descreve-se como as mulheres, após o diagnóstico do HTLV, colocam-se em uma situação distinta e inferior em relação à sociedade. Essa inferiorização se explica pelo fato de a estrutura social exigir dos indivíduos, principalmente das mulheres, um corpo fisicamente saudável, belo, forte e capaz de atender às demandas a ele impostas.

Realça-se, portanto, o quanto as limitações físicas intervêm na liberdade e privacidade, no lazer e o quanto a deficiência torna essas mulheres dependentes dos outros. Mudanças físicas trazem desconforto à paciente pela condição clínica e pela rotina imposta por suas alterações significativas, que repercutem na autoimagem e na vida cotidiana. Percebe-se que os sintomas influenciam diretamente na vida dos indivíduos soropositivos para o HTLV, dificultando ou até os impedindo de realizar tarefas básicas do seu cotidiano.

A perda da capacidade física ocasionada pela evolução da doença é sentida como perda do próprio sentido da vida. Para as mulheres, a perda do corpo sadio gera sentimentos de inutilidade, vergonha pessoal e social ${ }^{21}$. Afinal, em uma sociedade acostumada a rotular os indivíduos e a cultuar o corpo belo e aparentemente saudável, aqueles que portam alguma limitação física são rotulados pela sua deficiência e enxergados sob essa ótica.

No DSC3, o sofrimento marca a experiência vivida num passado alegre e divertido e a tristeza na vivência da atual situação. Mulheres soropositivas sintomáticas sentem que atrapalham a diversão de quem as acompanha, por causa das limitações físicas. Assim, a doença age como fator de ruptura de um fluxo cotidiano, fazendo a pessoa enferma necessitar reorganizar suas atividades diárias, e, às vezes, ocorre um distanciamento definitivo dessas atividades, sejam laborais ou sociais ${ }^{22}$.
Essas mudanças forçadas na vida das pessoas provocam sentimentos de diferença, inferioridade em relação a outras pessoas saudáveis, o que, por conseguinte, afeta a autoestima delas $^{23}$. A autoestima da mulher é diretamente comprometida, visto que ela sente necessidade de estar perfeita fisicamente, para aceitar-se e sentir-se aceita pela sociedade. Os efeitos negativos da doença são determinados diretamente pelo nível de restrição e incapacidade de exercer atividades essenciais à pessoa.

Não tendo a perspectiva de recuperação, resta à pessoa doente reestruturar-se para viver com qualidade, apesar das limitações e perdas impostas pela enfermidade que exige cuidado sistemático. Dessa forma, o paciente deverá familiarizar-se com a doença para viver de forma mais tranquila com a nova condiçã $0^{21}$.

Nesse contexto, evidencia-se a importância do apoio social à pessoa sintomática para o HTLV, mostrando-lhe a possibilidade de rearranjos nos projetos de vida pensados outrora, certificando-lhe que não é necessário rompê-los.

\section{CONCLUSÃO}

É perceptível o desconhecimento da sociedade, e até mesmo dos profissionais de saúde, acerca da infecção, prejudicando, assim, o correto aconselhamento, o tratamento e a adesão de políticas públicas para uma efetiva prevenção. Essa negligência se refere à realidade de ser uma doença de longo período de latência e prognóstico incerto.

A problemática do viver com o HTLV é abrangente e complexa, intervindo no cotidiano das pessoas soropositivas para o vírus, provocando mudanças muitas vezes radicais. Como evidenciado no estudo, tais mudanças abrangem fatores como relaxamento dos esfíncteres e diminuição ou perda dos movimentos dos membros inferiores.

Diante do explicitado, confirma-se a importância da produção científica, análise e discussão sobre o HTLV para o desenvolvimento de políticas e estratégias de saúde voltadas a esses indivíduos e aos profissionais de saúde que acompanham esses sujeitos. Nesse contexto, mostra-se relevante a atuação da enfermagem que deve estar inserida no cuidado às pessoas com doenças crônicas, destacando-se também a necessidade de fornecer mais esclarecimentos à população sobre o vírus, a fim de sanar dúvidas referentes à infecção e à sua relação com o HIV.

Por fim, assegura-se a convicção de que as discussões concernentes ao tema não devem findar-se com esse estudo, mas que este se constitua em fonte para pesquisas seguintes. É imperiosa a participação da enfermagem nessas pesquisas, pois apresenta-se como uma profissão histórica e culturalmente humanística por causa da relevante formação nessa área, o que faz esses profissionais estarem mais próximos do cuidado e com um olhar mais apurado para a necessidade de um cuidado holístico. 


\section{REFERÊNCIAS}

1. Carneiro-Proietti ABF, Ribas JGR, Catalan-Soares BC, Martins ML, Brito-Melo GEA, Martins-Filho AO, et al. Infecção e doença pelos vírus linfotrópicos humanos de células T (HTLV-I/II) no Brasil. Rev Soc Bras Med Trop. 2002;35(5):499-508. PMid:12621671. http://dx.doi.org/10.1590/ S0037-86822002000500013.

2. Brasil. Ministério da Saúde. Secretaria de Vigilância em Saúde. Programa Nacional de DST e Aids. Guia do manejo clínico do HTLV. Brasília: Ministério da Saúde; 2003. 52 p. (Série A. Normas e Manuais Técnicos) (Série Manuais; n. ${ }^{\circ} 3$ - CN-DST e Aids).

3. Silva ISP. Epidemiologia molecular do vírus Linfotrópico de células $\mathrm{T}$ humanas - HTLV 1/2 no estado do Amapá- Brasil [dissertação]. Macapá: Universidade Federal do Pará; 2006.

4. Bittencourt AL, Farré L. Leucemia/linfoma de células T do adulto. An Bras Dermatol. 2008;83(4):351-9. http://dx.doi.org/10.1590/S036505962008000400011 .

5. Teixeira MA. Soropositividade de mulheres para os vírus HIV e HTLV: significados do contágio do leite materno [tese]. Salvador: Universidade Federal da Bahia; 2009.

6. Catalan-Soares BC. Núcleos Familiares Infectados Pelo Vírus Linfotrópico de Células T Humanas: Determinantes Epidemiológicos e Genéticos (Belo Horizonte, 1997-2005) [tese]. Belo Horizonte: Universidade Federal de Minas Gerais; 2006

7. Shublaq MS. Avaliação da Capacidade Funcional e Qualidade de Vida em Pacientes com Mielopatia Associada ao HTLV-1 [dissertação]. Rio de Janeiro: Universidade do Rio de Janeiro; 2009.

8. Nogueira-Martins MCF, Bógus CM. Considerações sobre a metodologia qualitativa como recurso para o estudo das ações de humanização em saúde. Revista Saúde Soc. 2004;13(3):44-57. http://dx.doi.org/10.1590/ S0104-12902004000300006.

9. Lefévre F. Discurso do sujeito coletivo: um novo enfoque em pesquisa qualitativa. Caxias do Sul: Edues; 2005.

10. Zihlmann KF. Da invisibilidade à visibilidade do sujeito vivendo com a infecção/doença do vírus linfotrópico de células T humanas do tipo 1 (HTLV-1) e o lugar das decisões reprodutivas nas tramas do saber e do cuidar [tese]. São Paulo: Universidade de São Paulo; 2009.

11. Moreira CFC. Aconselhamento clínico de indivíduos infectados pelo HTLV [monografia]. Belo Horizonte: Universidade Federal de Minas Gerais; 2010.

12. Brasil. Ministério da Saúde. Departamento Nacional de Auditoria do SUS. Portaria $\mathrm{n}^{\circ} 1.376$, de 19 de novembro de 1993. Aprova alterações na Portaria n ${ }^{\circ} 721 / \mathrm{GM}$, de 09.08.89, que aprova Normas Técnicas para coleta, processamento e transfusão de sangue, componentes e derivados, e dá outras providências. Diário Oficial da União [Internet]. Brasília, de 2 dezembro de 1993 [citado em 2014 mar 15]. Disponível em: http://redsang. ial.sp.gov.br/site/docs_leis/ps/ps29.pdf

13. Grinover L. A hospitalidade urbana: acessibilidade, legibilidade e identidade. Rev Hosp. 2006;3(2):29-50.

14. Almeida PC, Aragão AEA, Pagliuca LMF, Macêdo KNF. Barreiras arquitetônicas no percurso do deficiente físico aos hospitais de Sobral, Ceará [Internet]. Rev Eletr Enf. 2006;8(2):205-12 [citado em 2014 mar 10]. Disponível em: http://www.fen.ufg.br/revista/revista8_2/v8n2a05.htm

15. Santos VS, Rivemales MCC. Facilidades e dificuldades encontradas na realização do aconselhamento às pessoas que vivem com HTLV [Internet]. Ciênc Cuid Saúde. 2012;11(3):542-48 [citado em 2014 abr 10]. Disponível: http://periodicos.uem.br/ojs/index.php/CiencCuidSaude/ article/viewFile/20262/pdf

16. Orge G, Travassos MJ, Bonfim T. Convivendo com o HTLV-I [Internet]. Gaz Méd Bahia. 2009;79(1):68-72. [citado em 2014 maio 10]. Disponível em: http://www.gmbahia.ufba.br/index.php/gmbahia/article/viewFile/1064/1033

17. Loureiro P. Infecção pelo HTLV-1: Diagnóstico e determinação da carga proviral em indivíduos assintomáticos e com enfermidades associadas em serviço de referência no Nordeste [tese]. Recife: Fundação Osvaldo Cruz; 2008.

18. Champs APS. Mielopatia associada ao HTLV-1: perfil clínico, epidemiológico e fatores prognósticos de incapacidade para marcha [dissertação]. Belo Horizonte: Universidade Federal de Minas Gerais; 2010.

19. Brito ES, Rabinovich EP. A família também adoece: mudanças secundárias à ocorrência de um acidente vascular encefálico na família. Interface Comunic Saúde Educ. 2008;12(27):783-94. http://dx.doi.org/10.1590/ S1414-32832008000400009.

20. Fonseca ESM, Camargo ALM, Castro RA, Sartori MGF, Fonseca MCM, Lima GR, et al. Validação do questionário de qualidade de vida em mulheres brasileiras com incontinência urinária. Rev Bras Ginecol Obstet. 2005;27(5):235-42. http://dx.doi.org/10.1590/S0100-72032005000500002.

21. Gascón MRP. Frequência de transtorno de humor e impacto na qualidade de vida dos pacientes portadores de HTLV-1 com Paraparesia Espástica Tropical [dissertação]. São Paulo: Secretaria da Saúde; 2010.

22. Rivemales MCC. Vivência da Sexualidade: Representações Sociais de Pessoas Soropositivas para o HTLV [tese]. Salvador: Universidade Federal da Bahia; 2013

23. Ramos IC, Queiroz MVO, Jorge MSB, Santos MLO. Portador de insuficiência renal crônica em hemodiálise: significados da experiência vivida na implementação do cuidado. Acta Sci Health Sci. 2008;30(1):73-9.

Recebido em: Dez. 29, 2016 Aprovado em: Fev. 25, 2017 